\title{
Patterns of Household Energy Consumption in Kathmandu
}

\author{
Surya Gyawali ${ }^{1 a}$, Sushil Bdr. Bajracharya ${ }^{1}$, Sudarshan Raj Tiwari ${ }^{1}$, Hans Norve Skotte ${ }^{2}$ \\ ${ }^{1}$ Department of Architecture, Pulchowk Campus, Institute of Engineering, TU, Nepal \\ ${ }^{2}$ Department of Architecture and Planning, NTNU, Trondheim, Norway \\ Corresponding author: agyawalisurya@ioe.edu.np
}

Received: Nov 2, 2018

Revised: Dec 24, 2018

Accepted: Dec 27, 2018

\begin{abstract}
Much of the world's energy is currently produced and consumed in ways that could not be sustained if technology were to remain constant and if overall quantities were to increase substantially. The objective of the paper is to examine the household energy consumption of the case study area. The paper also explores significant factors affecting energy saving measures at household level. A household questionnaire survey was conducted to identify energy consumption pattern and energy efficient measures. The study stabilized that, reducing the consumption of individual household energy by using energy efficient appliances and equipment is an obvious step for energy efficiency improvement. Results of the analysis revealed that electricity is predominately used for lighting and Liquefied Petroleum Gas (LPG) for cooking, the use of energy efficient lighting appliances increasing significantly. Also there is a strong relationship of monthly energy cost with number of family, occupied space and income. Based on the aforementioned result, it is clearly concluded that, in order to optimize energy use, appropriate energy efficient appliances are to be integrated into household level.
\end{abstract}

Key words: Household energy, energy consumption, energy efficiency, end-use energy

\section{Introduction}

Energy is indispensable in modern societies. Energy is needed for most of daily activities, such as lighting, cooking, heating/cooling, communication, transportation, and industrial processes to produce and supply commodities of our daily needs. Thus, energy is one of the most important indicators of socio-economic development, and per capita energy consumption is often viewed as a key index of the development. Developed countries have significantly higher per capita energy consumption. For example, the United States has a per capita energy consumption of $314.1 \mathrm{GJ} /$ year, Japan has $162.5 \mathrm{GJ} /$ year, and United Kingdom has $142.4 \mathrm{GJ} /$ year. For Nepal, the per capita total primary energy supply (TPES) is just $14.2 \mathrm{GJ} /$ year, which is far less than world's average per capita TPES of 76.6 GJ/year [3].

Energy consumption in the first eight month months of fiscal year 2015/16 has reached 10972.63 tons of oil equivalent (toe), which is 41.0 percent higher as compared to the same period of previous fiscal year. During the same period of previous fiscal year, the energy consumption was 7,781 toes. The consumption rate of traditional, commercial and renewable energy stood at 55.33 percent, 42 percent and 2.67 percent respectively. Such ratio in previous fiscal year had remained at 62.13 
percent, 35.87 percent and 1.99 percent respectively. This observation hints that traditional energy users are slowly attracted towards using petroleum products which are not produced in Nepal but to be imported [4].

According to Chapter 9 of Agenda 21(1992) protection of the Atmosphere,

"Energy is essential to economic and social development and improved quality of life. Much of the world's energy, however, is currently produced and consumed in ways that could not be sustained if technology were to remain constant and if overall quantities were to increase substantially. The need to control atmospheric emissions of greenhouse and other gases and substances will increasingly need to be based on efficiency in energy production, transmission, distribution and consumption, and on growing reliance on environmentally sound energy systems, particularly new and renewable sources of energy. All energy sources will need to be used in ways that respect the atmosphere, human health and the environment as a whole" [9].

To reduce the end-use energy consumption and Greenhouse gas (GHG) emissions from the residential sector, a large number of options need to be considered. These include improving the energy efficiency of houses through improving envelope characteristics; replacing existing heating equipment, household appliances and lighting with higher efficiency ones; and switching to less carbon-intensive fuels for space and domestic hot water heating. Energy-efficiency improvements have complex interrelated effects on the end-use energy consumptions of houses and the associated GHG emissions [1].

Due to increasing consumption of energy, the house owners need to be aware of house owner's practice that affects the energy consumption of residential building. Some of these are; use of energy efficient appliances, use of solar powered appliances etc. This paper highlights the current status of energy consumption by residential sectors in Kathmandu. It also elucidates the role of energy efficient appliances and use of solar powered appliances in order to reduce energy consumption in household level. The paper further tries to establish relation between household characteristic and energy consumption pattern. This study focused on determining the efficiency of above mentioned factors. The main objectives of this study are:

- To study the energy consumption pattern for end-use energy for households in study area.

- To examine significant factors affecting energy savings in the same households.

\section{Research Methodology}

Before describing the methodology used in this study to analyze factors which influence energy consumption in household level, a review of previous efforts to identify similar factors in household level is necessary. Improving energy efficiency and reducing energy demand are widely considered as the most promising, fastest, cheapest and safest means to mitigate climate change. Many opportunities appear to be cost-effective at current energy prices and can deliver additional benefits such as improved energy security, reduced fuel poverty and increased economic productivity [7]. From the literature review, there are certain factors potentially affecting energy consumption and energy saving in the urban residential areas. These factors consist of physical and structural, 
social and cultural, economic, communication and information, and psychological factors. First: physical and structural factors such as house type (single house, building, town house, apartment, rental house, and others, occupied space), location, number of household members, and household appliances. Second: social and cultural factors such as level of education and income/household. Third: Economic factors such as household expenditure. Fourth: communication and information factors such as industry source, government source, professional, interpersonal, law and regularity, government support, and public information, and last: psychological factors such as attitudes, knowledge, beliefs, and motives.

Ugursal and Fung [8] studied the interrelationship between energy consumption of buildings and appliance efficiency, and fuel substitution for space and domestic water heating. They conducted simulation studies using data from 937 homes located in different regions of Canada. The results of the study showed that appliance efficiency and fuel substitution could reduce energy consumption of the buildings [8]. Energy savings from replacing old appliances with high efficiency appliances was found to be less significant in comparison to that of fuel substitution. Another finding was that appliance efficiency coupled with improved home envelopes and heating/cooling systems could significantly save energy consumption [5].

From the literature reviews, this study proposes a theoretical framework on urban residential energy conservation. These are five factors potentially affecting energy consumption and energy saving in urban areas. The five consists of; physical and structural; social and cultural [6].

Sirchotpundit et al. [6] conducted a study to determine factors affecting energy consumption of households in Bangkok. The study shows that households used technological and alternative products for home energy saving are electrical saving label products or no. 5-saving-label products and Compact Fluorescent Lamp (CFL) bulbs equal to nearly a half of all types. Other products are Liquid Crystal Display and Light Emitting Diode (LCD \& LED) and Energy Efficiency Ratio (EER) products. These electric energy savings come from electrical saving label products, CFL bulbs, and auto power off equipment, LED light bulbs, and LCD \& LED televisions at an average rate of saving in reduction of household use between 2.66-5.29 percent.

\section{Data and Observation}

The factors affecting the household energy consumption were first examined and identified through a relevant literature review and by conducting a pilot survey. In a pilot study to determine the availability of the data for this paper, the author collected data from five house owners. Using the result of the pilot study, the final survey instrument was comprised of six major sections that relate to information of respondent, household characteristics, sources of end use energy, appliances characteristics and use, use of fans and heater, and monthly energy expenditure.

The questions in Section 1 of the survey were collected basic information of respondent such as name, age, education level and occupation. The questions of Section 2 were designed to determine the characteristics of household. In this section the author asked the respondent about the location, head of household, ownership of house, used floor area of house, number of occupants and monthly household income. The questions of Section 3 in the survey to determine the household energy sources by end-use for lighting, cooking, water heating, space heating and water pumping. The 
author designed some of the questions in accordance with a multiple choice format.

The questions of Section 4 and 5 in the questionnaire survey focused to determine number of electrical appliances and frequency of use of appliances and equipment. In Section 4 of the survey, questions were asked that were related to types of bulbs, induction cooker, water pump and computer. Section 5 of the survey, involved questions were asked that related to fans during the summer and heater during the winter such as number and frequency of use. The last Section of the survey, questions were asked that were related to monthly expenditure of electricity and LPG. Familiar non-technical terminology was used in order that house owners would easily understand the questions. The author also made to visit work place, a home visit or telephone call during data collection to verify that the home owners understood the questions correctly. Data were collected for 20 homes located in Kathmandu.

\section{Results}

Descriptive statistics comprises of frequency, distribution, measures of central tendency and dispersion e. g., percentage, maximum, minimum, mean and standard deviation used to summarize and describe data. Firstly, characteristics of household and its features has been analyzed. Secondly, household end-use energy source of lighting, cooking, water heating, space heating and water pumping has been summarized. In this section author intend is to find out dependency on fossil fuel (LPG) and solar energy (electrical and thermal). Furthermore survey results will illustrate the householder's awareness on use of energy efficient home appliances and relationship between monthly fuel cost to number of occupants, occupied floor area and monthly income. The findings of these analyses are described below.

\subsection{Basic Information of Respondent}

The study reveals that, 80 percent respondents are economically active middle aged between 26 to 59 years; 55 percent of them earned master or higher degree education; and 80 percent were service holders.

\subsection{Characteristics of Household}

Here, the characteristics of household have been shown. The percentage of head of household was 70 percent male and 30 percent female; the proportion the owned to rented ratio was 3:1. Only 10 percent respondent has occupied more than 3001 square feet floor area, others 30 percent of each used less than 1000, between 1001 and 2000, and between 2001 and 3000 square feet. 70 percent household size was found to compose of up to 5 members. According to monthly household income, 40 percent earned more than NRs 100,000 per month, other 40 percent earned between NRs 50,000 and NRs 100,000 per month, remaining earned less than NRs 50,000 per month.

\subsection{Household End use Energy Sources}

Fig. 1 shows that major portion of electricity and LPG used for lighting and cooking respectively. Whereas solar photovoltaic (PV) cell and solar collector used for lighting and water heating purpose. 


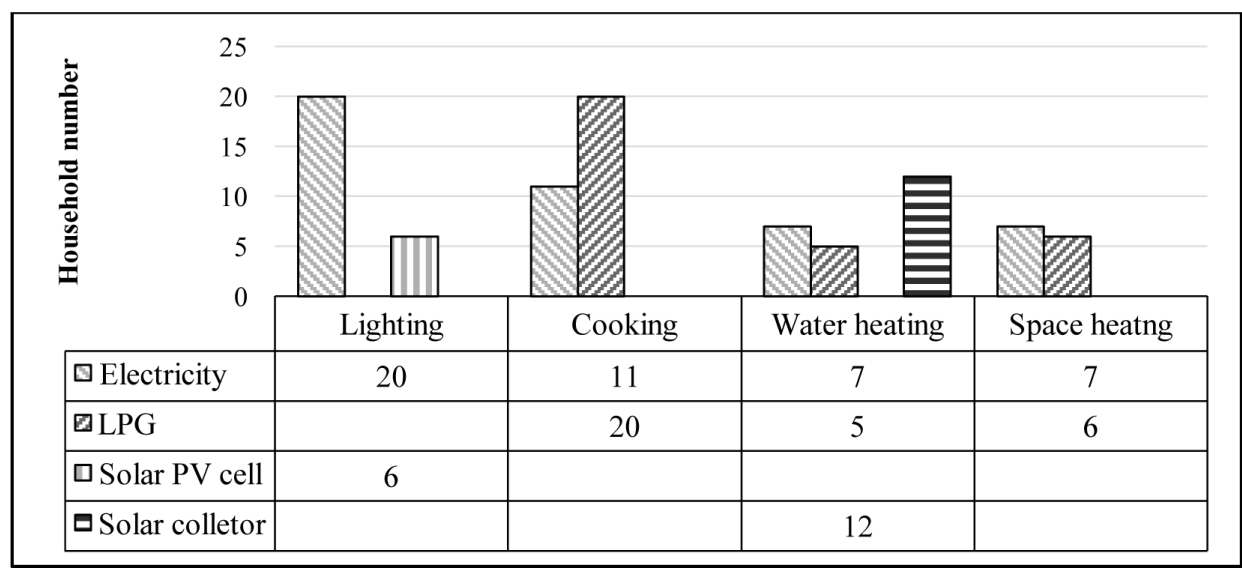

Fig. 1: Household energy sources by end use

\subsection{Household Energy Saving Light Appliances}

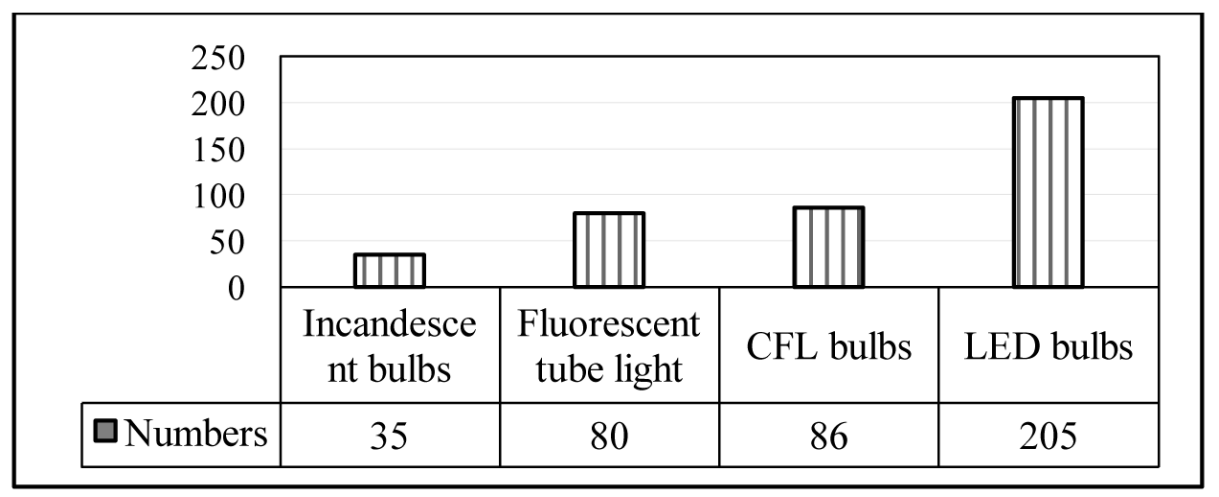

Fig. 2: Household lighting appliances

Fig. 2 clearly shows that the trend of using Light Emitting Diode (LED) is drastically increased. Data shows that the awareness level towards energy efficient lighting appliances has been increased, which will help to reduce household energy demand.

\subsection{Monthly Energy Cost}

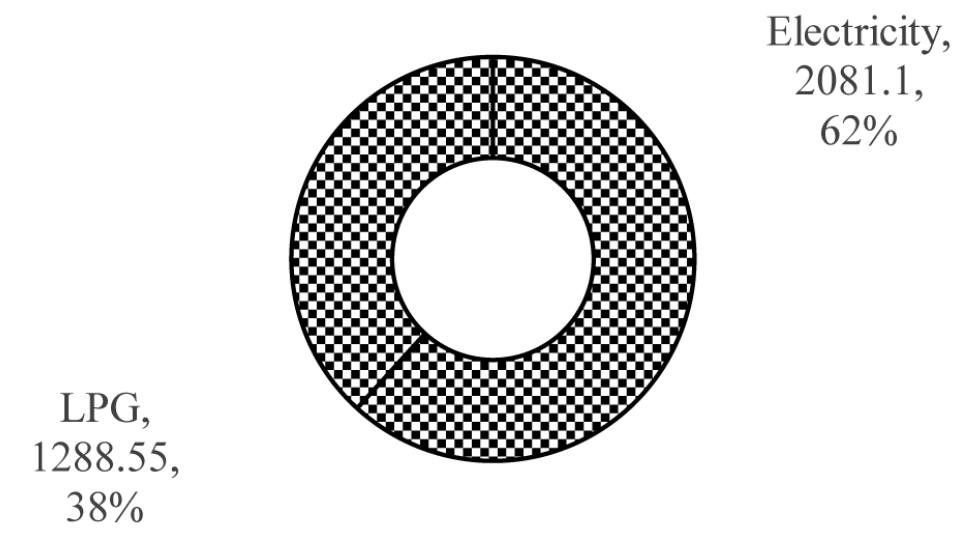

Fig. 3: Monthly average energy cost in NRs by fuel type 
Fig. 3 shows that monthly average energy cost for electricity is NRs 2081.1(62 percent) and LPG is NRs 1288.55 (38 percent). It shows that the dependency upon fossil fuel (LPG) is reduced.

\subsection{Relationship between Monthly Energy Cost and Number of People}

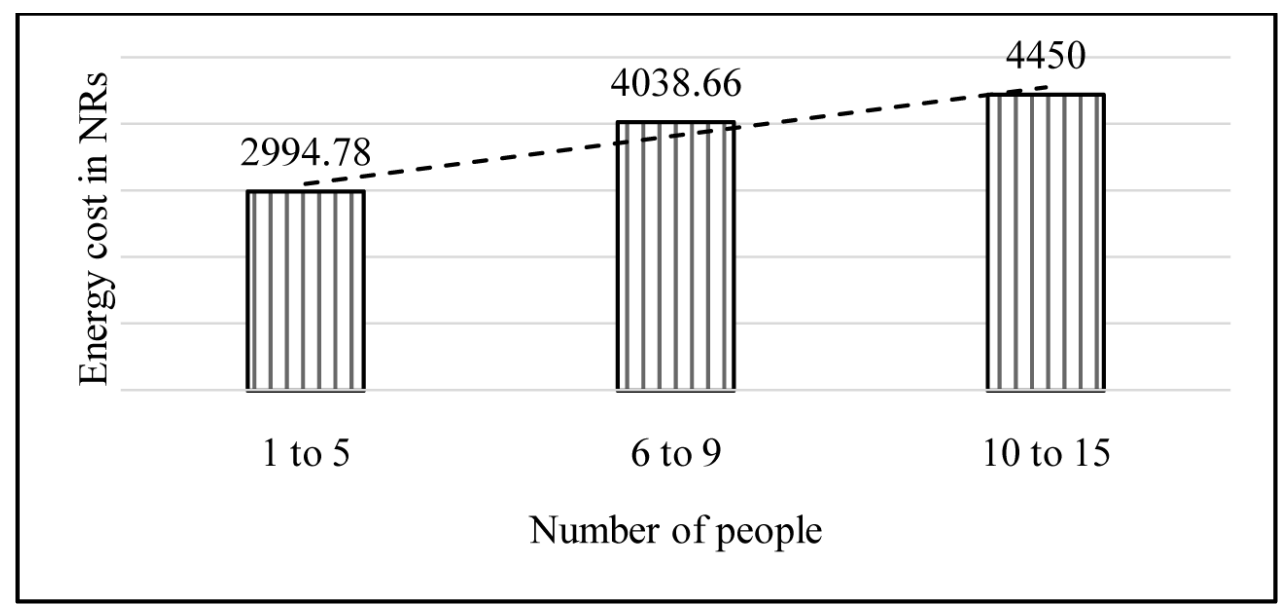

Fig. 4: Monthly average energy cost to household occupants

Household size simply refers to the number of people per household. Many researchers argue that occupancy has the strongest influence on variation in energy consumption [2]. Fig. 4 shows that household having occupant 10 to 15 expends NRs 4450 per month. This shows that energy cost varies according to family size.

\subsection{Relationship between Monthly Energy Cost and Occupied Floor Area}

Fig. 5 shows that the households having area more than 3000 square feet spent 5425 rupees for energy cost per month. The result shows that there are positive relationships between these variables.

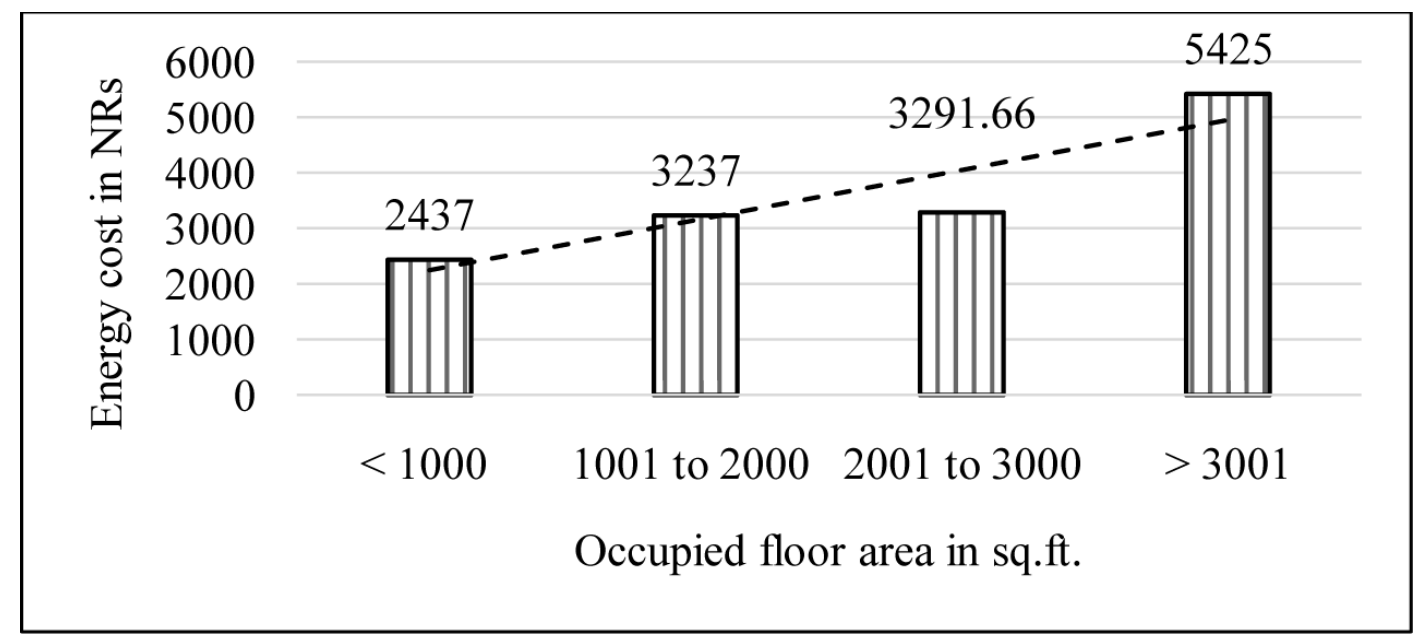

Fig. 5: Monthly average energy cost to occupied floor area 


\subsection{Relationship between Monthly Energy Cost and Income}

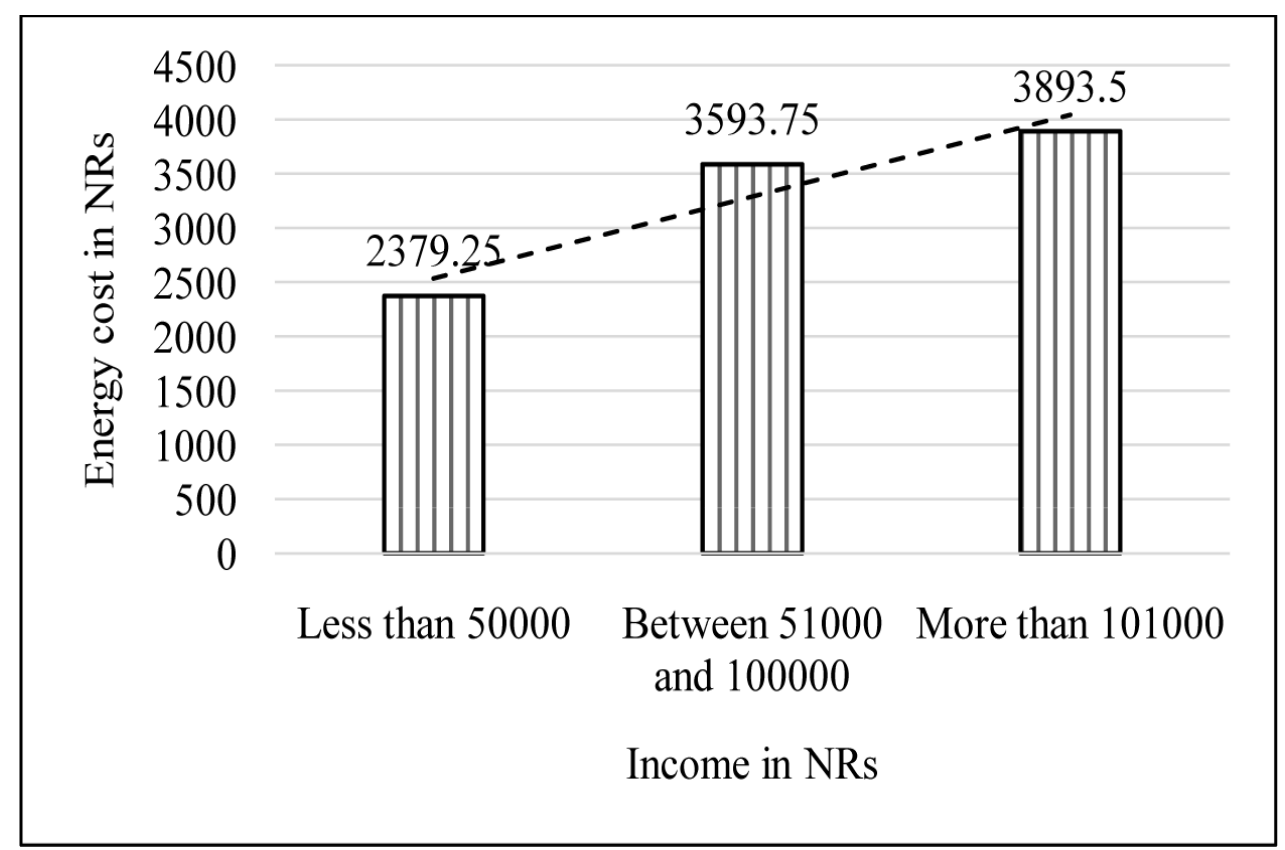

Fig. 6: Monthly average energy cost to income

Fig. 6 shows that the households having monthly income more than 101000 rupees spent 3893.5 rupees for energy cost per month. The result shows that there is strong relationship between these variables.

\section{Discussion}

This systematic analysis adds a holistic view of the energy consumption pattern for end use energy, examined significant factors effecting energy savings among of them comparison between lighting appliances were done. The author successfully performs an analysis of determining factors that have contributed to reduce household energy consumption and relationship between these factors. Based on the aforementioned discussion, it is clearly implicated that in order to optimize energy efficient energy consumption, appropriate energy efficient appliances are to be integrated. Further author should conduct in depth qualitative analysis to quantify the factors that could possibly affect household energy consumption and could affect energy efficiency.

Limitations of the Findings: These findings are based on sample size of 20 households located in Kathmandu. Electricity is predominately used for lighting and LPG for cooking. Extreme care should be exercised in the interpretation of this data in other context. The authors recognize that the findings are based on sample of one particular location of Kathmandu, so generalization of these results would not be possible.

Acknowledgements: The first author would like to thank all of the homeowners who were involved in the study for providing research data. 


\section{References}

[1] Aydinalp M, Ugursal VI and Fung AS (2002), Modeling of the appliance, lighting, and spacecooling energy consumptions in the residential sector using neural networks, Applied Energy, 71(2): 87-110.

[2] Bhattarcharjee S and Reichard G (2011), Socio-economic factor affecting individual household energy consumption: A systematic review, Proceedings of the ASME $20115^{\text {th }}$ International Conference on Energy Sustainability.

[3] KC S, Khanal SK, Shrestha P and Lamsal B (2011), Current status of renewable energy in Nepal: Opportunities and challenges, Renewable and Sustainable Energy Reviews, 15(8): 4107-4117

[4] Ministry of Finance (2016), Economic Survey 2015/16. Government of Nepal, Ministry of Finance

[5] Shrestha PP and Kulkarni P (2010), Identifying factors that affect the energy consumption of residential buildings, Construction Research Congress 2010.

[6] Sirchotpundit P, Poboon C, Bhanthumnavin D and Phoochinda W (2013), Factors affecting energy consumption of households in Bangkok metropolitan area, Environment and Natural Resources $J$, 11(1): 31-40.

[7] Sorrel S (2015), Reducing energy demand: A review of issues challenges and appliances, Renewable and Sustainable Energy Reviews, 47(2015): 74-82.

[8] Ugaulsal VI and Fung AS (1996), Impact of appliance efficiency and fuel substitution on residential and-use efficiency consumption in Canada, Energy and Buildings, 24(2): 137-146.

[9] United Nations Conference on Environment (1992), Agenda 21, Rio Declaration, Forest Principles, New York: United Nations. 